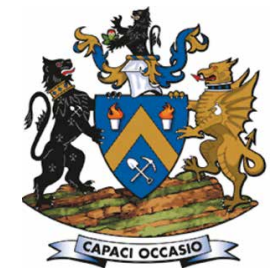

Affiliation:

1 University of Pretoria,

South Africa.

Correspondence to:

J. Uys

Email:

joeuys@lantic.net

Dates:

Received: 3 Oct. 2017 Revised: 29 Mar. 2019

Accepted: 25 Apr. 2019

Published: October 2019

How to cite:

Uys, J. and

Webber-Youngman, R.C.W.

A 4.0D leadership model

postualtion for the Fourth

Industrial Revolution relating to

the South African mining industry.

The Southern African Insitute of

Mining and Metallurgy

DOI ID:

http://dx.doi.org/10.17159/2411-

9717/17/450/2019

\section{A 4.0D leadership model postulation for the Fourth Industrial Revolution relating to the South African mining industry}

\section{J. Uys ${ }^{1}$ and R. Webber-Youngman ${ }^{1}$}

\begin{abstract}
Synopsis
The mining industry of the 21st century needs a new kind of leader as certain leadership styles and most leadership models currently employed in the world, and also in South Africa, are not sustainable. This article explores the historical leadership models that are now outdated and proposes a different approach in dealing with future leadership-related challenges. Questions are posed to explore leadership that can balance the leadership styles of the past (business acumen with technical capability on the one hand, and personality on the other hand) with increased intuitive discretion, a 'feel' for people and the future, and the ability to deal with complexity and to make timeous decisions to build organizational and industry resilience through the leadership characteristics identified. The question therefore arises: How are we going to manage and lead operations sustainably under these circumstances in future so as to deal with the challenges facing us in the Fourth Industrial Revolution? A new 4.0D Leadership model is proposed so as to increase appropriate leadership qualities (and therefore, industry effectiveness) in dealing with the challenges facing us in the Fourth Industrial Revolution.
\end{abstract}

\section{Keywords}

organization, leadership, industrial revolution, skills, 4.0D leadership, leadership behaviour.

\section{Introduction}

In 2016 the World Economic Forum published online an article written by Alex Gray with the title The 10 skills you need to thrive in the Fourth Industrial Revolution, this latest revolution being based on the use of cyber-physical systems. The First, Second, and Third Industrial Revolutions were based on mechanical production equipment driven by water and steam power, on mass production enabled by the division of labour and the use of electrical energy, and on the use of electronics and IT to further automate production, respectively. The ten skills listed by Gray (2016) that are required to thrive in the Fourth Industrial Revolution are as follows:

1. Complex problem-solving

2. Critical thinking

3. Creativity

4. People management (one could read leadership into this as well)

5. Coordinating with others (group work activities)

6. Emotional intelligence

7. Judgement and decision-making

8. Service orientation

9. Negotiating

10. Cognitive flexibility.

In another article, published in a South African newspaper, Beeld, on 23 January 2017 (Maake, 2017) the following were listed as things that machines will not be able to do in future (among others). The number in parentheses indicates the relative importance of the skill mentioned ( 1 being most important):

- $\quad$ Emotional intelligence (5)

- $\quad$ Creativity and innovation (4)

- $\quad$ Leadership (3)

- $\quad$ Adaptability (2)

- $\quad$ Problem solving (1). 


\section{A 4.0D leadership model postulation for the Fourth Industrial Revolution}

In Gray's article, people management (implying leadership as well) was listed as the fourth most important skill most likely to be needed, and in the newspaper article leadership was listed as number 3. Leadership's importance will probably rise even higher as the Fourth Industrial Revolution proceeds. With regard to the mining industry in particular, a more holistic approach to leadership, and how it will have to be realized, will be needed. Gray's (2016) article states that by 2020 the Fourth Industrial Revolution will have brought us, among other things, advanced robotics and autonomous transport, artificial intelligence and machine learning, advanced materials, biotechnology, and genomics. The successful implementation of these new developments will require a very different kind of leader. Consequently, the objective of this article is to investigate and propose the characteristics that will need to be associated with a leader in the Fourth Industrial Revolution.

Management/leadership will have to change and adapt to a new set of skills in order to be successful in the Fourth Industrial Revolution. The mining industry is in need of a new generation of innovative complex problem-solvers who also possess the other skills mentioned, and the quality of leaders with a new mind-set and related skills who will have to drive this revolution will determine the success thereof (Motsoeneng, Schultz, and Bezuidenhout, 2013).

The commodity pricing challenges experienced on a global scale in the mining industry in the last decade tested the resilience and endurance of most mining organizations. In South Africa especially, a number of mining houses had to drastically resize and restructure operations and staff. Future thinking succumbed, expansion plans were shelved, and other companies were either taken over or even ceased to operate (Marais, 2013).

Companies that survived and that are just getting over the difficult years are now facing a challenging future with regard to conventional methodologies and thinking, as posed by the current state of our mines and the expected challenges related to the Fourth Industrial Revolution. This potentially offers a new future, but also brings new challenges regarding the way in which mining will continue. The then Chamber of Mines of South Africa (2017), now the Minerals Council South Africa, indicates that modernization or next-generation mining will be needed to address rising costs and low productivity. It is therefore obvious that, in this context, the future mine will need a new kind of leadership to restore growth and sustainability in the mining industry. The qualities of mining leadership that will be needed in the future are agility and resilience, to create and maintain a state and culture of readiness (Malnight and van der Graaf, 2011). Companies must adapt to change by adopting solutions and innovations in the areas of robotics, disruptive technologies, new ecosystemic operations, and many more. It will be necessary to extend beyond the current fixed value chains, shifting in knowledge away from production points to off-site transorganizational knowledge hubs and shared services.

In a 2017 PwC publication titled: 'We need to talk about the future of mining' (2017, pp. 18-19), it is stated that:

'Technology can become a fundamental success factor. This is a world where "leading practice", not "best practice" is the goal. Rapid advancements in technology - such as robotics, remote operations, drones, machine learning and blockchains - mean the innovations that are cutting edge today might not even exist in five or ten years' time. So how do you build that flexibility into your mine plan and capital plan (as well as your workforce) if you're developing a mine that will run for 20 or more years? There is a fundamental mismatch between the lifecycle of mining assets and the lifecycle of technologies and digital enablement that is disrupting the sector.'

Apart from the future of technology in mining, the economic downturn has also exposed leadership in the mining industry or the lack thereof. Trying to singularly define new horizons of leadership for the future in mining is going to become one of the biggest challenges ever faced (Denton and Vloeberghs, 2003).

Moreover, the future of leadership in mining and other industries is going to be very different from the traditional hierarchical structures on offer. The privilege of rank in an organizational hierarchy, which provides the incumbent with leadership status and a leadership 'seat' and its associated command and control authority, has no future in the mining industry. There is therefore a need to rethink the required leadership skills for miners and leaders as perceived and those that are needed to thrive in the Fourth Industrial Revolution in many ways that do not exist today. This will, however, be needed within the very near future. Such an ability to undergo rapid change is traditionally not a common characteristic in the mining industry and is less common among current leadership pacemakers in the industry (Schultz and Bezuidenhout, 2014).

The mining industry has developed and entrenched a command and control culture. Transformation will be essential to cope with the social and technological demands inherent in future mining operational landscapes, as well as resilient and agile leadership (Maruping, 2012).

\section{A historical overview of the theories of leadership and leadership models}

\section{Developmental timelines}

Leadership has always been a topic of interest in organizations, societies, communities, and nations. Just as managers in organizations want to explain and understand personality, so do they want to understand and explain leaders and leadership. With the advent of the use of psychometrics to measure personality and behaviour, leadership theories abounded (Scouller, 2011).

Current leadership theories, mostly developed and postulated in the previous century, underscore the understanding of leadership as a stable series of combinations of personal attributes. These are all based on personality typologies, cognitive sets, and behavioural patterns responsive to circumstances and environments as they had prevailed for decades at that time. A great number of theories were developed and formulated and many of them are clustered around common principles.

\section{'Great Man' theories (1840s)}

During the 1840s, psychology was in its infancy and psychometrics was not advanced, yet leadership was studied and described. At the time three kinds of leadership were studied military, political, and royal. 'Great Man' theories were based on the assumption (mainly from studying royal households) that great leaders are born and not nurtured or developed. Leadership was therefore intrinsic to an individual's genetic makeup. The term 'Great Man' was coined in terms of gender and stems largely from military leaders since soldiering was an exclusively male occupation.

\section{Trait theories (1930s-1940s)}

A century later, as psychology developed leadership theories 


\section{A 4.0D leadership model postulation for the Fourth Industrial Revolution}

and research gained momentum, the next generation of theories can be classified as (albeit similar in many ways to Great Man theories) the so-called 'trait theories'. These assume that some people inherit certain qualities and traits that make them better suited to leadership than other people. They assume that intrinsic qualities such as intelligence, a sense of duty and responsibility, extraversion, creativity, confidence, and even values, in a composite manner, define the traits of a leader. Matthews, Deary, and Whiteman (2003, p. 3) cite American psychologist Gordon Allport who '... identified almost 18000 English personalityrelevant terms ...'.

The main criticism levelled against the trait theories is simply that there are vast numbers of people who possess these traits associated with leadership, yet not everyone possessing these qualities seeks out such positions or aspires to these levels of leadership. The central question raised by opponents of the trait theory is simply: 'If particular traits are key features of leadership, then how do we explain people who possess those qualities but are not leaders?' Scouller (2011) also points out that trait theory had not really arrived at a full list of the desired leadership qualities that could be used as the basis for isolating leadership qualities and characteristics.

\section{Behavioural theories of leadership (1940s-1950s)}

Psychology as a science, and research within the subject, has given rise to more sophisticated psychometrics, especially through statistical methods incorporating factor analyses that would enable more accurate pinpointing of critical leadership variables in people. These measurements gave rise to the behavioural theories of leadership, which stipulated that leaders are made, not born. This approach was diametrically opposed to the theories of the previous century. These leadership theories focused on the actions of successful leaders, not on their mental qualities or internal states, and led to the rise of behaviourism, which asserts that people can be trained ('conditioned' in behavioural terms) to become leaders. Leadership, according to the behaviourists, is thus either taught or acquired through observing the behaviours of role models (Spillane, Halverson, and Diamond, 2004). Following from this, behavioural theories of leadership therefore encompass what leaders do, and how the behaviours and actions of successful leaders differ from those of unsuccessful leaders (Smit et al., 2013).

\section{Contingency theories (1960s) and situational theories (1970s)}

Contingency theories of leadership suggest that a particular leader and leadership style are adopted as being the most appropriate or most likely to achieve the most successful outcome, given the specific variables in a particular environment. This theory is a bit more complex than the previous theories since it expands beyond the individual's traits and behaviours to consider also a number of external variables, such as the qualities of the followers, as well as aspects of the work situation, for instance (Smit et al., 2013). Situational theories merely expand the contingency theories to encompass the specific appropriateness of the various styles to a particular situation, for example, authoritarian (e.g. in a crisis) $v s$. participative (e.g. a team context). These theories are based on the assumption of behaviour control: leaders can change their behaviour at will to meet different circumstances. However, in practice, many leaders find this hard to do. Even after lengthy and intense training, leaders fall back on old behaviours, since unconscious and fixed beliefs, fears, or ingrained habits really dictate behaviour (Scouller, 2011).

\section{Transformational theories (1980s)}

Transformational theories, also known as relationship theories, focus on the interactions between leaders and followers. This results in a solid relationship where the main compass of such a relationship is trust. Transformational leaders gain from this trust, increase levels of motivation, and thus enable themselves to inspire people by helping group members see the importance and meaning of the task at hand. These leaders are focused people who are fulfilling their potential, but also, through the performance of the group, accomplish the required task at hand (Smit et al., 2013).

A challenging aspect of transformational theories is the notion of the inspirational natures and charismatic personalities of these leaders through which they transform their followers. Not all leaders can acquire these qualities and therefore elements of the trait theory still remain here. Leaders are also not always aware of the specific requirements of the transformational behaviours and the requirements of the situation in play (Bezuidenhout and Schultz, 2013). Furthermore, because rules and regulations are flexible, rather than guided by group norms, the likelihood of coercion and manipulation is a risk. While these attributes may very well provide a sense of belonging for the followers as they can easily identify with the leader and the purpose of this leadership, they can also lead to corruption and deviant group norms.

\section{Relevance of the theories of leadership and leadership models for the future}

Although these theories have contributed immensely to the understanding and development of leadership, and have been applied for a long time, they have also led to conventional thinking about leadership in a conventional world mind-set. This situation is confirmed by the 2017 Project Charter: Human Factors of the South African Mining Extraction, Research, Development and Innovation (SAMERDI, 2017, pp. 3, 4). This states: 'The South African mining landscape is littered with examples of failure of new technology implementation. The reasons for these failures have in the main been due to human factors rather than failure of the technology itself'. It also states that 'Many of these issues are legacy issues, which are derived from a history of "management knows best", and a fear of involvement of organised labour in discussions or designs that ultimately affect them more than anyone else.'

'Management knows best' refers to the current frame of reference with regard to leadership. Leadership in mining in the South African context has created a culture that is slow to change and slow to respond by doing things differently. These comfort zones, and the apparent inability of leadership in the mining industry to make a paradigm shift, are hampering what we believe is the required future leadership model for mining.

The mining industry of the 21 st century requires a new kind of leader, because the business of mining is the business of people. The extractive activities merely represent the playing field of practising this 'people business'. How the extraction and work is going to be done in 10 to 20 years' time will be radically different from current mining practices. Concomitantly, the changing situation of leadership for the future needs to be addressed now (Schultz et al., 2014).

The current leadership theories are mostly two-dimensional, namely work and people. If one wants to push the envelope, a possible third dimension, such as a specific situation, can be 


\section{A 4.0D leadership model postulation for the Fourth Industrial Revolution}

added. Yet all the current leadership theories remain in a biaxial mode, a Y- and an X-axis. Most of these theories date from the previous century and not many new leadership models have been developed during the last few decades. Certainly there has been nothing new since the dawn of the new millennium.

A new leadership postulation is therefore needed to cope with the challenges relating to the Fourth Industrial Revolution - one that explains leadership in new and rapidly changing contexts, one that balances work and people with leadership impact, one that has a solid foundation of balance between individual leadership and prowess and, finally, one that clearly spells out leadership direction and objectives as a compass to resilience and yet is adaptive and agile.

\section{New leadership postulation: the 4.0D leadership model for the future}

Schultz and Bezuidenhout (2014) ungroup the various leadership clusters and theories into a number of styles, ranging from bottom-up leadership to transformational leadership, charismatic leadership, authentic leadership, and transactional leadership, but they fail to include servant leadership as postulated by Blanchard and Hodges (2003). In analysing the various personality traits of each style, Schultz and Bezuidenhout (2014) clearly follow the path of trait theory leadership.

Although these styles and style-specific descriptors come in very handy to describe leadership behaviour, essentially they do not address the fundamentals of leadership. The main reason for this is that a style is an outcome of the function of other human dynamics embedded in the intrapersonal makeup and composition of an individual. Secondly, future leadership requirements tend rather to indicate the need for a new model as a point of departure for formulating a leadership approach. This needs to be independent of a specific leadership style and approach to work and people only - it needs to transcend the biaxial designs of the past.

Currently in leadership development there is a plethora of programmes focusing on a variety of factors that influence leadership, e.g. emotional intelligence - commonly referred to as EQ as coined by Daniel Goleman (1995), and other motivational aspects related to leaders with visionary thinking (Schultz and Bezuidenhout, 2014). Nicholls (1994) describes a three-tier leadership approach which essentially attempts to integrate the three basic intrapersonal dynamics of individuals: the head, which relates to strategic leadership; the heart, which is linked to inspirational leaders; and lastly the hands, which encompasses the actions and task execution of the supervisory leader.

Furthermore, there was a definite trend in the later part of the previous century to focus on leadership styles as an apt way to analyse how leaders function in organizations. Raza (2019) lists these styles as:
1. Autocratic leadership
2. Democratic leadership
3. Strategic leadership style
4. Transformational leadership
5. Team leadership
6. Cross-cultural leadership
7. Facilitative leadership
8. Laissez-faire leadership
9. Transactional leadership
10. Coaching leadership
11. Charismatic leadership
12. Visionary leadership.

Many other leadership styles are also described as leadership solutions for organizations. Most notable of these is Goulston's (2009) heartfelt leadership, which focuses mainly on emotional connectivity between leaders and followers in the form of caring and trust.

All of the above approaches, developmental lines, and theories of leadership are very valid and until now served leadership (to a large extent) very well. What is very evident in all these approaches is the lack of integration of leadership theories and styles, and this may perhaps be the single element that is needed to bind these leadership theories and styles together. It is therefore suggested that the lack of an integrated leadership model creates diversity in approaches. This diversity is so extensive that the expected future leadership challenges and landscapes may never be addressed in a fitting manner with the required outcomes.

\section{Elements of the 4.0D leadership model}

Following from the discussions above, an integrated leadership model is now postulated that is independent and not affiliated to any of the leadership theories, and that does not prescribe any style as a single solution. The model is multidimensional and expands beyond the world of work and people; it links leadership in future contexts and it aligns various, up-to-now isolated, elements in a cohesive manner.

\section{First dimension - The base: Where leadership begins - the SELF}

Leadership starts with the SELF, which represents the intrapersonal dimension of the leader. The basic components of any individual lie within the following psychological triad.

> Cognition: This relates to intellectual functioning. Its taxonomy was first described by educational psychologists (Bloom et al., 1956) and 45 years later was revised by Anderson and Krathwohl (2001). The taxonomy of the cognitive domain comprises the following (in order of increasing complexity):

- Remembering: Recognizing and recalling knowledge from memory, i.e. remembering previously learned information and being able to produce or retrieve definitions, facts, or lists from memory.

- Understanding: Constructing meaning from a variety of functions such as written or graphic messages, and activities like interpreting, exemplifying, classifying, summarizing, inferring, comparing, or explaining.

- Applying: Executing or implementing using a specific procedure. This step implies situations where learned material is used in products such as models, presentations, interviews, or simulations.

- Analysing: Separating information or concepts into parts to determine how various parts relate to or interrelate with one another, or how the parts relate to an overall structure or purpose; also to differentiate, organize, and attribute, as well as being able to distinguish between the various parts or components that make up the mental actions of this function.

- Evaluating: Judgement based on criteria and standards by checking and evaluating reports and critiques, recommendations, and reports - examples of outcomes that demonstrate the processes of evaluation. In this taxonomy, evaluating is precursory behaviour before something is created. 


\section{A 4.0D leadership model postulation for the Fourth Industrial Revolution}

- Creating: Grouping elements to form a coherent or functional unit or whole. This entails reorganizing elements into new patterns or structures through generating a plan or formulating a way forward. It requires that parts are put together either in a new way, or synthesised into a new and different form or product. This process is the highest order of cognition and the most difficult mental function in the new taxonomy.

-Affect: Affective states are a psycho-social construct and 'affect' refers to the emotional functioning of the individual which usually 'kicks in' before the cognitive process becomes active. It has three basic dimensions:

- Valence: Emotional valence refers to the consequent emotions elicited by a certain situation, as well as emotion-eliciting circumstances (Harmon-Jones, Gable, and Price, 2013). These are subjective feelings or affect-based attitudes and may or may not be related to the actual situation - they are subject to the individual's emotional state and wellbeing.

- Arousal: This physiological response occurs as an often-subconscious response to affective interpretation of a stimulus, and has a scaled result or control mechanism that varies from extreme arousal on the one hand, to complete immobilization on the other hand (Blechman, 1990).

- Motivational intensity: Gable and Harmon-Jones (2013) found that affective states with high motivational intensity cause a narrow attention scope (a focused state with the aim of zooming in on the goal or object needed or desired). Affective states with low motivational intensity cause relatively broad attention scope (a relaxed state in which the scope broadens to seek new opportunities).

- Behaviour (conation): Conation is the third faculty of the mind (Atman, 1987) and is the result of the interactive working of the cognition and affect. It therefore represents the subsequent behaviour - how affect and cognition translate into the individual's behaviour (Bagozzi, 1992).

A fundamental principle of the 4.0D leadership model is that the interactive balance between the triad of Affect, Behaviour (conation), and Cognition (the A-B-C) must ideally be perfect (or at least strive to strike a synergistic balance between the aspects of the triad). Hence the assertion as basic principle of this model - that leadership starts with the notion of SELF that forms the base of the model, as shown in Figure 1.

The components of the base, however, do not function in isolation but, as explained in the previous sections, the aspects of the triad of the SELF (A-B-C) interact with each other. An acceptable SELF implies a balanced-based triangle, meaning a congruent condition, and any incongruence implies an imbalance. The base (from a personal perspective) may therefore need intervention to restore the balance and congruency. The lines of interaction are as follows.

\section{A-B line: Affect interacts with behaviour}

The outcome of this interaction is widely seen in the domain of the transformational and charismatic leadership styles; the central leadership behavioural theme is inspiration.

\section{A-C line: Affect interacts with cognition}

The resultant dynamic of the interaction between rationality and emotion is emotional intelligence (EQ field of leadership behaviours). Styles that would fit in this dynamic line could be the authentic leadership and transactional leadership styles. A democratic bottom-up style behavioural continuum would fit in here.

\section{B-C line: Behaviour interacts with cognition}

The outcome of behaviour (conation) combined with the outcome of cognition (rationality) leads to the arena of leadership motivation (of self, others, units, or organizations). The leadership styles that would emerge on the behavioural continuum would be authoritarian and directive leadership styles. These can therefore be illustrated as shown in Figure 2.

The three lines between the various points in Figure 2 can be termed 'dynamic lines', these being the motivation dynamic line, the EQ dynamic line, and the inspirational or impact dynamic line. With the base (shown in red and numbered as 1 in Figure 3 ) complete, the 4.0D leadership model then postulates that from these dynamic lines three 'panels' arise to point $\mathrm{D}$ and form a tetrahedron (or triangular pyramid), which is illustrated in Figure 3.

\section{A}

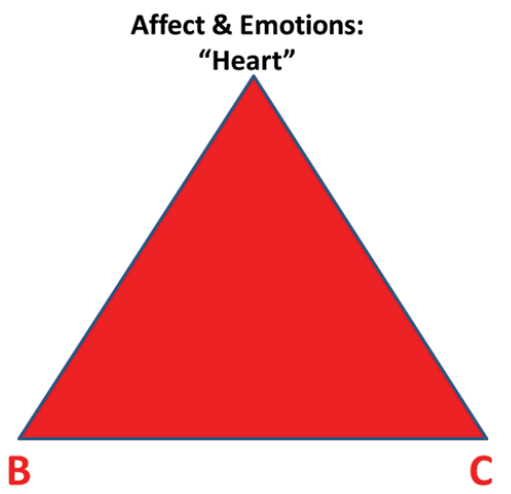

Behaviour \&

Conation: "Hands"
Cognitive \&

Rational: "Head"
Figure 1-The base and its A-B-C: The 'SELF'

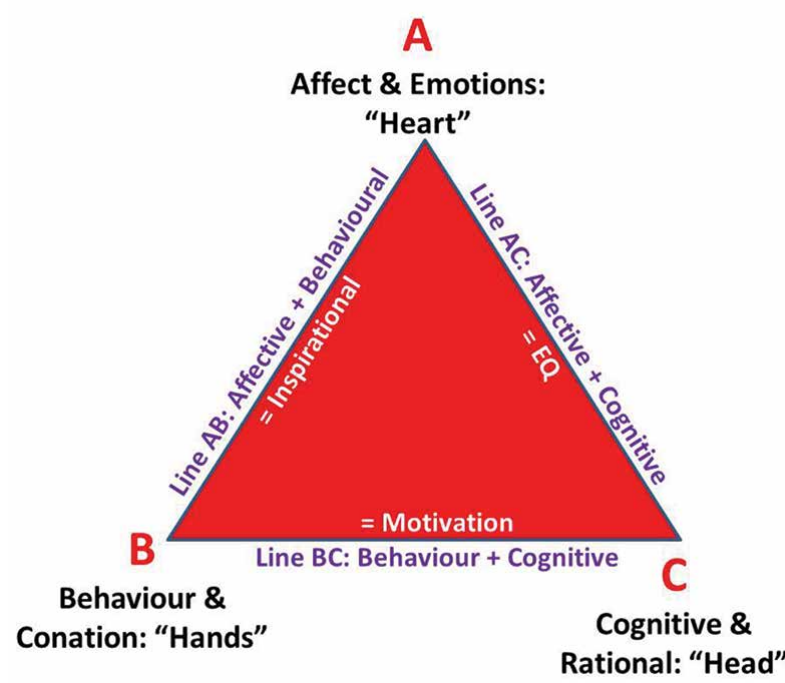

Figure 2-The SELF as base with the interactive lines 


\section{A 4.0D leadership model postulation for the Fourth Industrial Revolution}

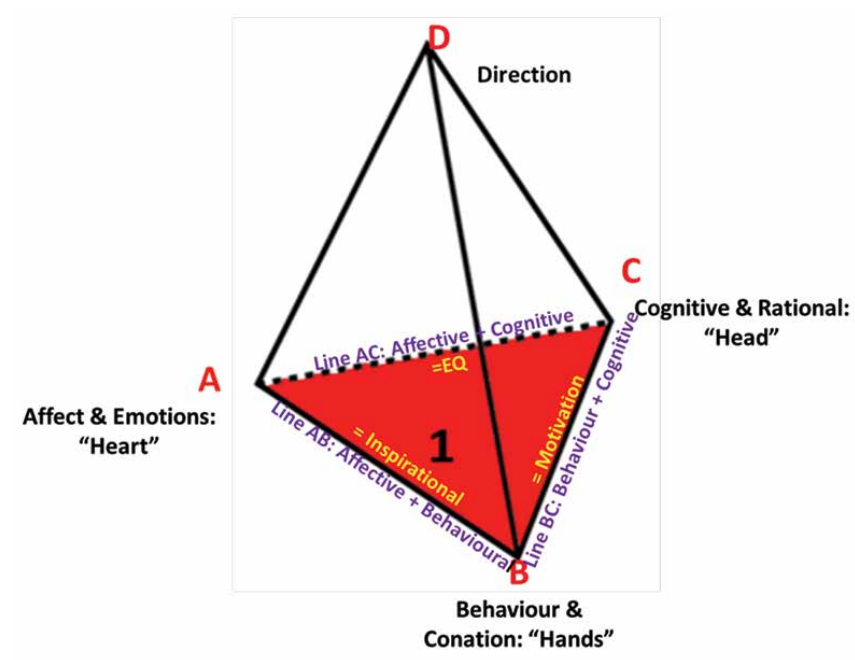

Figure 3-The SELF (A-B-C) with the three related panels

As a result of the dynamic lines with their associated behavioural continuums, there would be a visible leadership effect of focus. The base creates leadership meaning in three facets in the following manner.

\section{B-C line: Behaviour interacts with cognition}

Leadership manifests in the context of the business environment, internal organization, the external environment, the business playing field, and technical prowess. This panel is termed the 'WORK panel' (shown in purple and numbered as panel 2, B-C-D) and represents the WORK (vocational) domain as illustrated in Figure 4.

\section{A-C line: Affect interacts with cognition}

The social dimension includes leadership in the context of the interpersonal domain, with reference to leading people and teams, formal and informal relationships, as well as building organizational culture. Here we refer to 'people leadership'. It is termed the PEOPLE panel (shown in brown and numbered as panel 3, A-C-D) as illustrated in Figure 5.

\section{A-B line: Affect interacts with behaviour}

The dynamic line for leadership behaviour related to Affect and Behaviour is known as the impact dimension. It entails leadership in the context of having a meaningful impact on the community, and on internal and external stakeholders (whether they are antagonistic or protagonistic), and alludes to the leader's legacy on a variety of levels. We refer to this panel as the leadership IMPACT panel (shown in green and numbered as panel 4, A-B-D) as illustrated in Figure 6.

\section{The APEX}

The final component is the APEX (D), whose base is the SELF, which forms the foundation from which the three panels join at the top. All the panels and the base must be in balance for leadership harmony and integration. The apex of the 4.0D leadership model also indicates leadership direction. It represents the unification of the SELF and the organizational direction in the form of the visionary futuristic dimension. This encompasses leadership in the context of the future, with reference to integration between personal and organizational

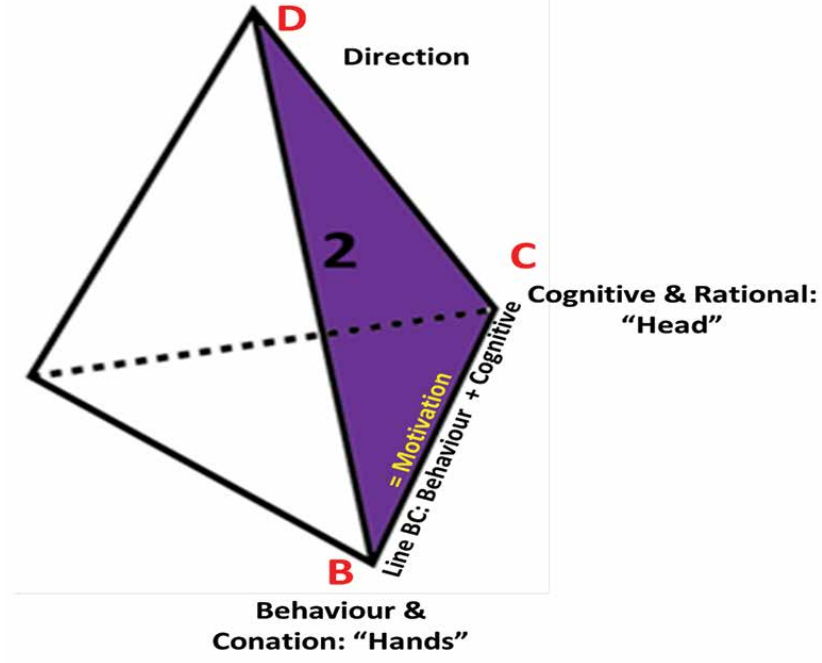

Figure 4-The WORK panel (B-C-D)

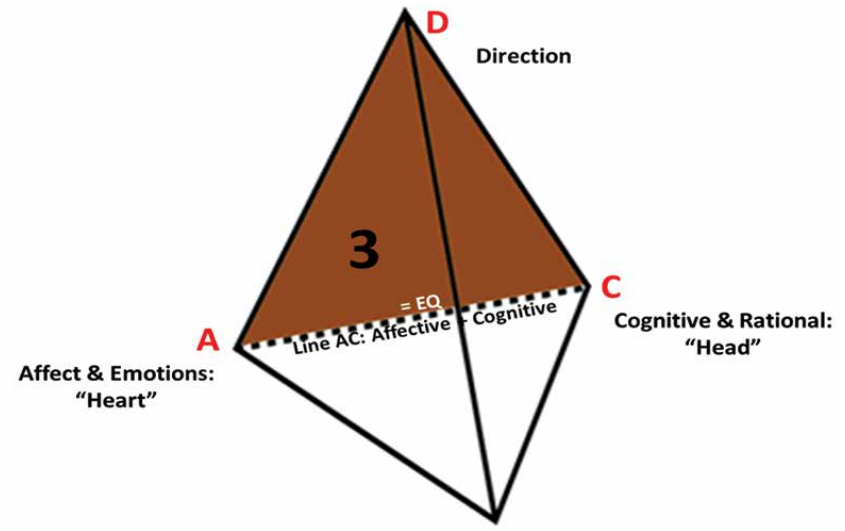

Figure 5-The PEOPLE panel (A-C-D)

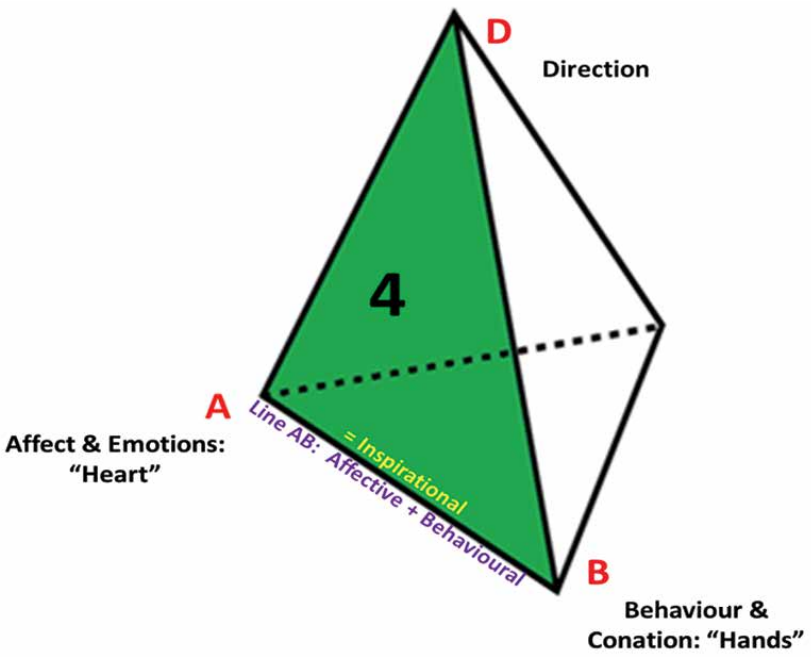

Figure 6-The IMPACT panel (A-B-D)

visions, missions, and values. The volume within the pyramid also implies increasing levels of leadership complexity. Optimal balance of the pyramid is achieved when leaders within organizations, executives, and boards formulate transparent, 


\section{A 4.0D leadership model postulation for the Fourth Industrial Revolution}

ethical, principled, virtuous, and honest apexes. This reflects a values-driven type of leadership, supported by a sound base and three integrated panels as illustrated in Figure 7.

\section{Understanding the 4.0D leadership model postulation}

The 4.0D leadership model postulated is a model of balance of human dynamics at the base and of congruence of the rising panels. It integrates a variety of human elements into a working tool for leadership development that needs identification. It could also be used to identify individual leadership flaws and for diagnosing underdeveloped leadership dimensions. If one or more panels are out of balance and/or the base is skewed, sustainable leadership will be adversely affected. An extreme imbalance can even cause the pyramid to topple over and a disintegrating base will cause the 'collapse' of leadership.

Congruence between the panels therefore needs constant attention by the leader and by the organization. This will assist in monitoring the development of the leader and as the complexity of the leadership role changes, the size ('volume') of the 4.0D model should also change accordingly.

The complexity of change results directly in the changes to the required apex formulations that the leader must make - thus the apex of the CEO requires a greater 'volume' in the 4.0D pyramid than the 'volume' of the middle manager, whose apex will be tactical as compared to the strategic apex of the CEO, as illustrated in Figure 8.

The 4.0D leadership model also aims to integrate a variety of separate points of leadership. While many programmes see $\mathrm{EQ}$, for example, as the solution to leadership challenges, the contextual fit with other human dynamics is rarely assessed. With the base and three panels, the model offers an integrative

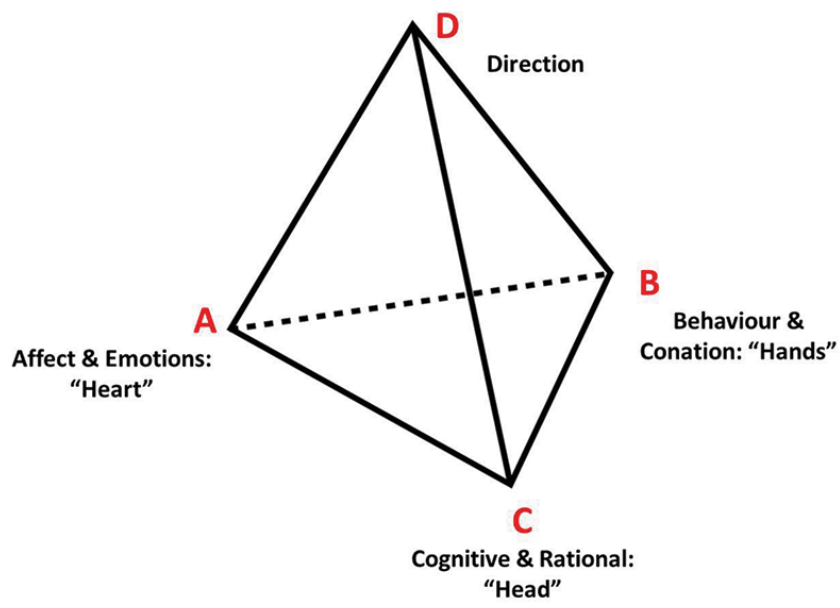

Figure 7-The 4.0D leadership model approach. Since such an approach also accommodates most of the leadership styles already discussed, it does not exclude any style, behaviour, contingency, or trait.

\section{Application in industry}

The 4.0D leadership model is a new postulation and is deemed to be epistemologically intact since the design stems from many decades of work by the authors in the leadership landscape of specifically the mining industry as well as the manufacturing contexts. It has been applied for more than a year in a South African gold mining company on three levels - namely executive, middle, and senior as well as emerging and junior. The initial results seem to hold positive spinoffs for individuals as well as their organizations. Expansions into the aviation industry and the human resources fields are being investigated, as well as into the copper and platinum mining industry globally.

\section{Conclusions}

> It is evident that over the years there were several different types and theories of leadership style, each specific and relevant in terms of its timeline in history.

> In terms of the challenges associated with the Fourth Industrial Revolution and its expected complexities, a new type of leadership model was needed.

> The elements of the new 4.0D leadership model include a base and three panels making up a triangular pyramid or tetrahedron

> The base of the pyramid is the SELF, which represents the intrapersonal dimension of the leader. The basic components of any individual (or the self) lie within the psychological triad of Affect, Conation (Behaviour), and Cognition.

$>$ The three sides that make up the leadership pyramid are represented by three panels, namely the vocational (WORK), the PEOPLE, and the IMPACT panels.

- A fundamental principle of the 4.0D leadership model is that the interactive 'balance' between Affect, Behaviour, and Cognition (the A-B-C) must ideally be perfect (or at least strive to strike a synergistic balance between the aspects of the triad), hence the assertion that leadership starts with the SELF (the base of the model).

- The 4.0D leadership model postulated is a model of the balance of human dynamics at the base and of congruence of the rising panels. It integrates a variety of human elements into a working tool for identifying individual leadership flaws and for diagnosing underdeveloped leadership dimensions.
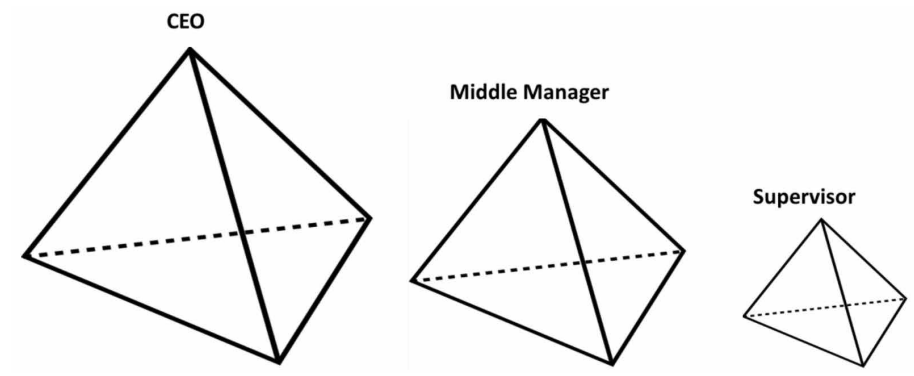

Figure 8-The 4.0D leadership model in various complexity settings 


\section{A 4.0D leadership model postulation for the Fourth Industrial Revolution}

- The complexity of change taking place results directly in the required changes to the apex formulations that the leader must make.

It was highlighted in the article that historically the mining industry has developed and entrenched a command and control culture, which needs urgent transformation. This is essential to cope with the social and technological demands inherent in future mining operational landscapes, specifically with regard to sustainability and agility in terms of leadership.

It was furthermore stated that the challenges associated with the Fourth Industrial Revolution will in future need a different kind of leadership model. The 4.0D leadership model shown in this article, through its multidimensional and integrated approach in terms of leadership development, offers a potential solution to addressing the leadership challenges facing the mining industry in future.

\section{Suggestions for further work}

Due to the novelty of the model proposed, it is in the process of being tested and applied in the mining industry. It is therefore implied that this model will be appropriate for the mining industry and will be tested in terms of its applicability and its successful implementation, and adjustments may have to be made.

\section{References}

Anderson, L.W. and Krathwohl, D.R. (eds). (2001). A Taxonomy for Learning, Teaching, and Assessing: A Revision of Bloom's Taxonomy of Educational Objectives. Longman, New York.

Atman, K.S. 1987. The role of conation (striving) in the distance education enterprise. American Journal of Distance Education, vol. 1, no. 1. pp. 14-24.

BAgozzl, R. 1992. The self-regulation of attitudes, intentions, and behavior. Social Psychology Quarterly, vol. 55, no. 2. pp. 178-204.

Bezuidenhout, A. and Schultz, C. 2013. Transformational leadership and employee engagement in the mining industry. Journal of Contemporary Management, vol. 10, no. 1. pp. 279-297.

Blanchard, K. and Hodges, P. 2003. The Servant Leader. Thomas Nelson, Nashville, TN.

Blechman, E.A. 1990. Moods, Affect and Emotions. Lawrence Erlbaum Associates, Hillsdale, NJ.

Bloom, B., Englehart, M. Furst, E., Hill, W., and Krathwohl, D. 1956. Taxonomy of Educational Objectives: The Classification of Educational Goals. Handbook I: Cognitive Domain. Longmans, Green, New York, Toronto.

Chamber of Mines of South Africa. 2017. Modernisation: Towards the mine of tomorrow. Fact sheet 2017. Johannesburg.

Denton, M. and Vloeberghs, D. 2003. Leadership challenges for organisations in the New South Africa. Leadership \& Organization Development Journal, vol. 24 no. 2. pp. 84-95. doi: 10.1108/01437730310463279

Gable, P.A. and Harmon-Jones, E. 2013. Does arousal per se account for the influence of appetitive stimuli on attentional scope and the late positive potential? Psychophysiology, vol. 50, no. 4. pp. 344-350.
Goleman, D. 1995. Emotional Intelligence: Why It Can Matter More Than IQ. Bantam Books, New York.

Goulston, M. 2009. Just Listen: Discover the Secret to Getting Through to Absolutely Anyone. AMACOM; Special editor edition. New York, NY.

GraY, A. 2016. The 10 skills you need to thrive in the fourth industrial revolution. World Economic Forum, Cologny, Switzerland.

Harmon-Jones, E., Gable, P.A., and Price, T.F. 2013. Does negative affect always narrow and positive affect always broaden the mind? Considering the influence of motivational intensity on cognitive scope. Current Directions in Psychological Science, vol. 22, no. 4. pp. 301-307.

MAAкE, I. 2017. Take wat nie deur 'n masjien gedoen kan word nie. Beeld, 23 January 2017. p. 4

MALNIGHT, T. and van DER GRAAF, K. 2011. Leadership challenges in South Africa: A land of contradictions. Trip summary insights report. Leading in a Connected Future (LCF) Insights \#2011-004. https://pdfs.semanticscholar.org/727a/ ad7472ec948b175b036d96b5ae1a96bcd2a9.pdf [accessed 6 March 2019].

Marais, L. 2013. The impact of mine downscaling on the Free State goldfields. Urban Forum, vol. 24. pp. 503-521. doi:10.1007/s12132-013-9191-3

MARuping, P. 2012. The Mining Sector Innovation Strategies Implementation Plan. 2012/13 - 2016/17. Technology Innovation Agency, Pretoria.

Matthews, G, Deary, I.J., and Whiteman, M.C. 2003. Personality Traits. 2nd edn. Cambridge University Press, Cambridge, UK.

Motsoeneng, L., Schultz, C,. and Bezuidenhout, A. 2013. Skills needed by engineers in the platinum mining industry in South Africa. UNISA. http://uir.unisa. ac.za/bitstream/handle/10500/13876/13R0045M\%20Picmet\%20Artikel_ Motsoeneng.pdf? sequence $=1$

Nicholss, J. 1994. The "heart, head and hands" of transforming leadership. Leadership \& Organization Development, vol. 15, no. 6. pp. 8-15.

PwC. 2017. We need to talk about the future of mining. https://www.pwc.com/gx/ en/energy-utilities-mining/assets/pwc-mining-transformation-final.pdf

RAZA, A, 2019. 12 different types of leadership styles. https://wisetoast.com/12different-types-of-leadership-styles/

SAMERDI. 2017. Project Charter: Human Factors of the South African Mining Extraction, Research Development and Innovation (SAMERDI) strategy. Johannesburg.

Schultz, C. and Bezuidenhout, A. 2014. A leadership initiative to enhance employee engagement amongst engineers at a gold mining plant in South Africa. UNISA. http://uir.unisa.ac.za/bitstream/handle/10500/13883/Picmet\%20artikel\%20 Leadership\%20initiative\%20_Anglo.pdf? sequence=1\&isAllowed=y

ScoulLeR, J. 2011. The Three Levels of Leadership: How to Develop your Leadership Presence, Knowhow and Skill. Kemble, UK.

Smit, P.J., Cronje, G.J., Brevis, T., and VRBA, M.J. 2013. Management Principles: A Contemporary Edition for South Africa. 5th edn. Juta, Cape Town.

Spillane, J.P., Halverson, R., and Diamond, J.B. 2004. Towards a theory of leadership practice. Journal of Curriculum Studies, vol. 36, no. 1. pp. 3-34. doi:10.1080/00 22027032000106726 